\title{
Sujeito lírico de Mario Quintana: o velho diante do espelho
}

\author{
Nathalia Sabino Ribas*
}

\begin{abstract}
Resumo: Com base no estudo de Salete de Almeida Cara sobre a poesia lírica moderna, observa-se os recursos estilísticos utilizados por Mario Quintana na caracterização do sujeito poético de sua obra, quando este é considerado velho. Além disso, analisa-se a forma pela qual a velhice é representada na poesia do autor, verificando-se em que medida o eu-lírico resgata e/ou preserva traços pueris nessa fase da vida. O presente ensaio, ao propor uma reflexão sobre o modo pelo qual o envelhecimento humano é abordado na lírica brasileira contemporânea, contribui para o preenchimento de uma lacuna existente, por parte dos estudos literários, em relação a esse tema crucial para o qual a sociedade é cada vez mais sensibilizada.
\end{abstract}

\begin{abstract}
Based on the study by Salete de Almeida Cara about modern lyric poetry, this article observes the stylistic resources used by Mario Quintana in the characterization of the poetic subject in his work, in a time when it is considered old. Besides that, it analyses the way old age is represented in the author's poetry, verifying to what extent the lyric self recovers or preserves the childish features in this time of life. While promoting a reflexion about human aging, this essay reflects upon the ways old age is approached in contemporary Brazilian lyric, a crucial theme on which society has focused more and more
\end{abstract} which society has focused more and more

Palavras-chave: Envelhecimento humano; Lírica; Mario Quintana.

\section{A poesia não espelha a realidade}

Na ocasião da morte de Mario Quintana, o jornal Zero Hora publicou em sua homenagem, uma matéria intitulada "O anjo disfarçado tinha jeito de guri e rosto de avô". A expressão aqui grifada fora dita pelo escritor Erico Verissimo, que, no texto de abertura de Pé de Pilão, assim definiu o colega de ofício: "Quintana, na verdade, é um anjo disfarçado de homem. Às vezes, quando ele se descuida ao vestir o casaco, suas asas ficam de fora". Doze anos mais tarde, em comemoração ao centenário de nascimento do poeta, o mesmo jornal ${ }^{1}$ traz de novo o tema do anjo associado ao seu nome, tratando da tendência romântica em se confundir a biografia do escritor com aspectos de sua obra. De fato, a recorrência da figura do

\footnotetext{
* Nathalia Sabino Ribas possui graduação em Letras pela Universidade de Passo Fundo (2005). Atualmente é aluna regular do Mestrado em Letras/ Estudos Literários da UPF, professora titular da Oficina Literária da Coordenadoria de Atenção ao Idoso de Passo Fundo e coordenadora do Circuito de Cinema Dati-Sesc. Tem experiência em pesquisa na área de Letras, com ênfase em Literatura Brasileira.
}

1. MOREIRA, Carlos André. O lugar a que pertence o poeta. Zero Hora, Porto Alegre, 18 fev. 2006. 
anjo em muitos de seus poemas fez com que Quintana passasse a ser visto como um "anjo poeta", alcunha mais conhecida no imaginário popular do que a própria obra, conforme destaca Tânia Franco Carvalhal ${ }^{2}$.

Paulo Becker, autor de uma destacada investigação crítica sobre Mario Quintana, explica que "o desejo de enraizar sua poesia na experiência vivida aproxima o poeta dos românticos, que almejavam a unificação entre vida e arte, daí produzirem obras abertamente confessionais" (BECKER, 1996, p. 20). Sobre essa identificação entre produções do imaginário e realidade, Salete de Almeida Cara afirma, porém, que "mesmo naqueles textos para cuja total compreensão a biografia do autor pode ajudar o 'eu' que fala no poema, a subjetividade, não se refere apenas àquele que escreveu o texto" (CARA, 1985, p. 47). Assim, por mais que o tom da obra seja confessional, o sujeito lírico não pode ser confundido com o poeta em carne e osso, na medida em que é criado através das escolhas de linguagem, da melodia, do canto, da sintaxe, do ritmo que o texto apresenta (Cf. CARA, 1985, p. 47-48).

$\mathrm{O}$ objetivo deste ensaio, portanto, não consiste em observar se o escritor que acreditava ser "preciso conservar a criança dentro de si", pois aqui a poesia será considerada um espaço possível de liberdade e não o espaço da realidade ou do "eu" (Cf. CARA, 1985, p. 48). O que se busca analisar são os recursos estilísticos utilizados por Mario Quintana, na caracterização do sujeito poético de sua obra, quando este é considerado velho. Também fará parte do exame a observação da forma pela qual a velhice é representada na poesia de Quintana, verificando-se em que medida o eu-lírico conserva e/ou resgata traços pueris no alto de sua idade avançada. O presente ensaio, ao propor uma reflexão sobre o modo pelo qual o envelhecimento humano é abordado na lírica brasileira contemporânea, contribui para o abalo à "conspiração do silêncio", denunciada por Simone de Beauvoir (1990, p. 106), sobre esta "metamorfose" que é a velhice.

\section{0 olhar poético lançado ao velho: em busca de imagens da velhice}

2. Em colaboração ao artigo O lugar a que pertence o poeta. Zero Hora, Porto Alegre, 18 fev. 2006.

3. Ao entrevistar o escritor Fernando Sabino, Hermes Rodrigues Nery cita a frase que ouviu certa vez de Mario Quintana. Disponível em <http://medei.sites.uol.com.br/penazul/geral/entrevis/sabino.htm>. Acesso em 20 abr. 2006. 
Para introduzir a análise, toma-se o poema "Envelhecer" (p. 174) ${ }^{4}$, que, "sem comprometer sua complexidade intrínseca, sintetiza em apenas quatro versos toda uma fase da vida humana" (BECKER, 1996, p. 130). Nesse quarteto, o sujeito poético compara o passar do tempo a uma estrada de mão dupla, resumindo a juventude como uma trilha para novas descobertas e a velhice, como um atalho para o isolamento e a morte. O eu-lírico, no entanto, não demonstra qualquer tipo de desespero frente a este último "caminho". Ao contrário, fala dele com profunda resignação, convivendo em harmonia com as metamorfoses que o passar do tempo traz:

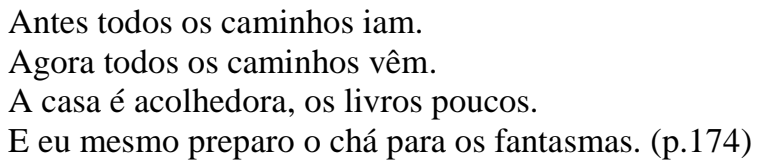

Estabelecendo-se um diálogo entre esse quarteto e o poema "Do mal da velhice" (p. 226), tem-se um contraponto, pois este sujeito poético demonstra maior dificuldade em aceitar o peso da idade. Desde o título, torna-se evidente o desprezo com que ele aborda a questão da velhice, vista como uma fase em que as pessoas deixam de viver e passam apenas a encompridar "ainda mais" a "doença" que a velhice representa. Em outras palavras, entendese que para esse sujeito lírico a longevidade é um "mal" a ser "combatido":

\footnotetext{
Chega a velhice um dia... E a gente ainda pensa

Que vive... E adora ainda mais a vida!

Como o enfermo que em vez de dar combate à doença

Busca torná-la ainda mais comprida... (p.226)
}

Quintana também concede bom humor ao tema da velhice, utilizando a ironia como recurso para "expressar um conceito positivo mas deixar subentendido outro, negativo" (BECKER, 1996, p. 141), como mostra ao compor este trecho de "Reflexos, Reflexões..." (p. 543): "Velhice é quando um dia as moças começam a nos tratar com respeito e os rapazes sem respeito nenhum" (p.543). Nota-se nesse fragmento o humor ferino que é uma das marcas da produção literária do poeta, mas, apesar de seu caráter jocoso, o trecho não deixa de denunciar o preconceito das gerações mais novas em relação ao velho, que é taxado de impotente e, por conseqüência, improdutivo.

Outro assunto relacionado à maturidade que recebe igual atenção por parte da lírica quintaniana é a questão "Da experiência" (p. 229). No quarteto assim intitulado, o acúmulo de conhecimentos que o eu-lírico faz com o passar dos anos vem novamente ligado ao campo semântico da palavra doença. Segundo o poema, a experiência de vida é tão útil ao velho

4. Neste trabalho, todas as citações da obra do autor foram retiradas da seguinte edição: QUINTANA, Mario. Poesia completa. Rio de Janeiro: Nova Aguilar, 2005. 
quanto é, para o "doente perdido", a receita forjada pelo "médico tardio". Tem-se aqui, mais uma vez, a aproximação da figura do velho à imagem do enfermo em fase terminal:

A experiência de nada serve à gente.

É um médico tardio, distraído:

Põe-se a forjar receitas quando o doente

Já está perdido... (p. 229)

A propósito, a idéia de que a espera pela morte é a única coisa que resta ao velho tem destaque em "Cadeira de Balanço" (p. 448). O poema relata a rotina de algumas avozinhas que passam seus dias "na velha cadeira em que a morte as embala". É a estereotipada imagem de velhas inúteis que aparece no poema, ao lado do conceito de ociosidade que lhes é creditado; elas que têm como único compromisso a "hora da sesta". Uma vez que "seus pensamentos já não têm sentido", resta-lhes somente a fuga "deste lado do mundo", a qual se dá por meio do sonho, talvez uma forma de estarem mortas por pelo menos alguns instantes, ou quiçá, a única forma de estarem vivas em meio à solidão da "deserta sala onde o relógio marca a nenhuma hora":

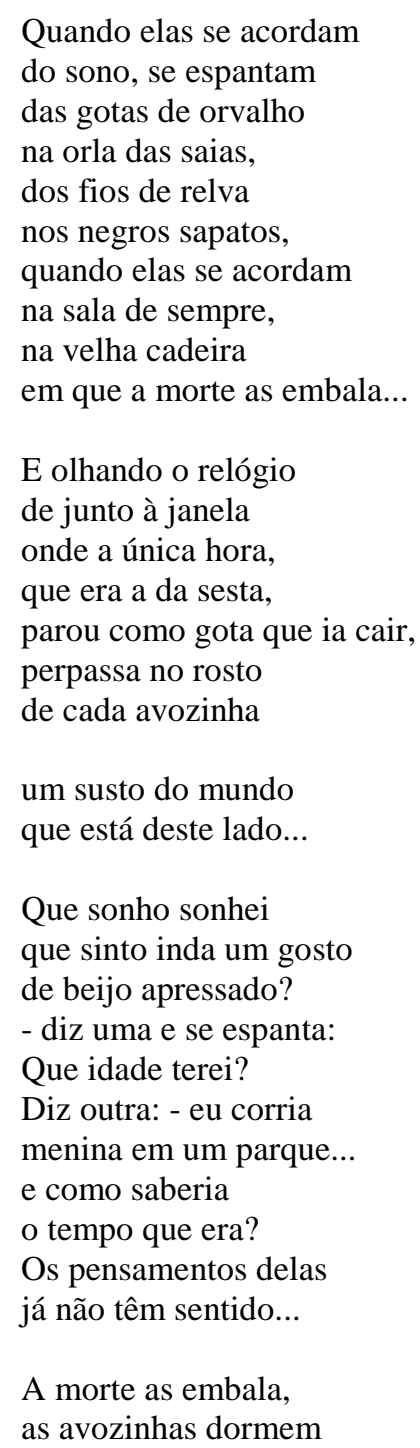




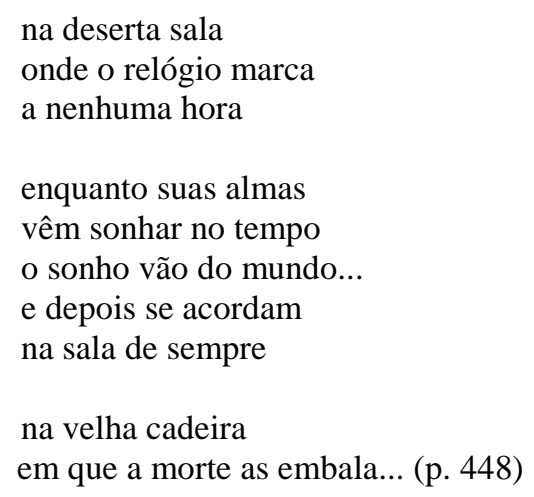

$\mathrm{Na}$ obra de Mario Quintana, há ainda um soneto que relata a surpresa do eulírico ao deparar-se com sua imagem refletida no espelho:

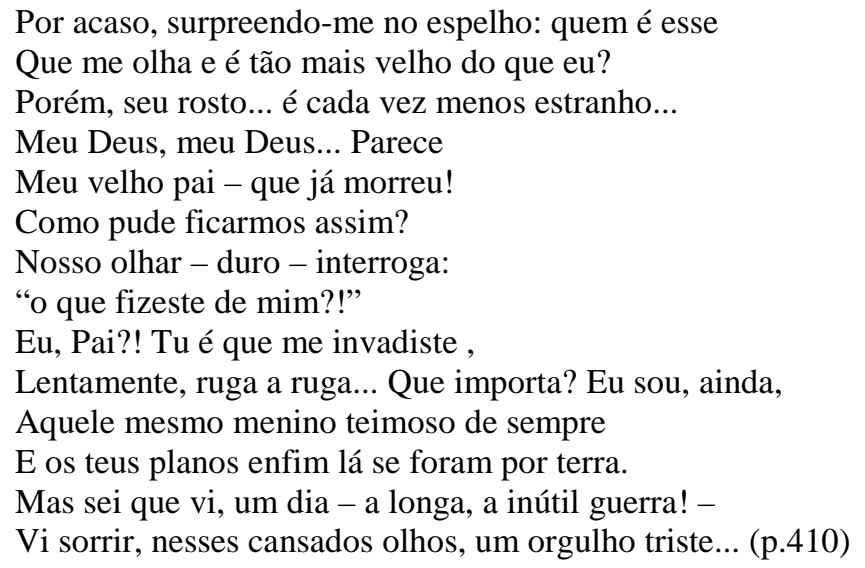

Admirado por constatar ali um "rosto onde escorre o tempo" (p. 392), o sujeito lírico questiona: “quem é esse/ Que me olha e é tão mais velho do que eu?”. Cabe comentar que a parte grifada neste verso, transcrito de "O velho do espelho" (p. 410), acaba lembrando a estrutura sintática, rítmica e sonora da pergunta que a madrasta de Branca de Neve faz tantas vezes diante de seu Espelho Mágico (este é o título de um dos livros de Quintana): “existe alguém no mundo mais belo do que eu?". De certo modo, pode-se dizer que o espelho no qual o sujeito poético se observa também é mágico, pois, através dele, consegue estabelecer um encontro imaginário com o "velho pai que já morreu", agora fundido em seu próprio perfil. Essa fusão é expressa no verso "Como pude ficarmos assim?", por meio da proposital discordância entre o sujeito na $1^{\text {a }}$ pessoa do singular e o verbo conjugado na $1^{\text {a }}$ pessoa do plural. Outra marca lingüística que denota a contração dos descendentes numa só imagem pode ser encontrada no seguinte trecho: "Nosso olhar - duro - interroga: 'o que fizeste de mim?!"”. Essa pergunta, dirigida de pai para filho e vice-versa, é respondida pelo "mesmo menino teimoso de sempre", que se defende: "Eu, Pai?! Tu é que me invadiste,/ Lentamente, ruga a ruga...".

"Quem disse que eu me mudei?" (p. 760) é outro poema que ecoa a voz de um sujeito poético envelhecido, conforme nos indica a expressão "velha casa", presente no segundo 
verso: "Não importa que a tenham demolido:/ A gente continua morando na velha casa em que nasceu" (p. 760). Ao que parece, o dístico evidencia a "velha casa" como uma metáfora para a transfiguração que o corpo do sujeito poético sofre com a chegada da velhice, pois, assim como "a velha casa demolida" ainda é capaz de abrigar a infância do eu-lírico, a carcaça gasta pelo tempo também continua acolhendo a mesma alma imutável de sempre. Além disso, o eu-lírico demonstra ter preservado uma capacidade lúdica que se apresenta de forma acentuada na infância, quando se é capaz de deslocar-se no tempo e no espaço por meio do imaginário.

Entre os textos líricos de Mario Quintana, que se referem ao tema da morada encontra-se, ainda, “A casa grande” (p. 479), que relata a vontade frustrada do sujeito lírico de ter como berço "uma dessas casas de meia-água" em vez de "um solar de leões":

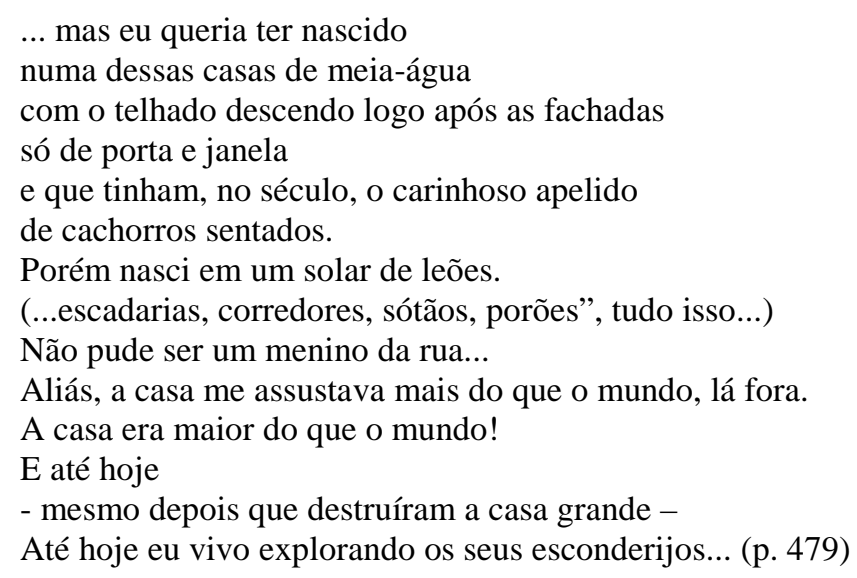

Com base nas construções que o poema apresenta, é possível afirmar que a singeleza e a simplicidade do "cachorro sentado" - a casa em que queria ter nascido - se contrapõe à grandeza esmagadora e assustadora, mas que também fascina, da casa de leões em que de fato nasceu. A proteção paradoxalmente ameaçadora da casa de leões tirou do eu-lírico a chance de explorar "o mundo lá fora", de ser "um menino da rua", condição, aliás, muito diversa da do "menino de rua", alguém explorado por aquele mesmo mundo externo. Esse menino, a exemplo do eu-lírico de "Quem disse que eu me mudei?", também se desloca no tempo e no espaço, a fim de continuar vasculhando os "esconderijos" da casa antiga, que agora não existe em outro lugar senão em sua memória.

Mas, se nesses dois casos a ludicidade é encarada como algo positivo, capaz de fazer o sujeito poético ultrapassar as fronteiras físicas e temporais a seu próprio gosto, por outro lado, ela pode representar um fardo pesado demais para alguém maduro, conforme é possível verificar em “Das Ilusões” (p. 214):

Meu saco de ilusões, bem cheio tive-o.

Com ele ia subindo a ladeira da vida.

E, no entretanto, após cada ilusão perdida... 
Que extraordinária sensação de alívio. (p. 214)

Destaca-se, nesse quarteto, a metáfora do amadurecimento como uma estrada íngreme sobre a qual o eu-lírico deixa cair suas ilusões sempre que se depara com a realidade. Ao que parece, a decepção é encarada com resignação pelo sujeito poético, como algo necessário a sua evolução enquanto indivíduo, o que, de certo modo, vem ao encontro das teses freudianas sobre a repressão do princípio do prazer pelo princípio da realidade, compensada, no caso acima, pela "extraordinária sensação de alívio" que ele experimenta.

Já o eu-lírico presente no "Soneto XVII" (p. 101) relembra com certa melancolia as frustrações que sofrera, pois, a partir delas, perdeu não só o "jeito de sorrir que tinha", mas também a confiança no outro. Esse receio em relação às intenções alheias é generalizado pelo emprego do sujeito indeterminado, que se liga aos verbos "assassinaram", "mataram", bem como à locução verbal "foram levando", encontrados neste primeiro quarteto:

Da primeira vez em que me assassinaram

Perdi um jeito de sorrir que eu tinha...

Depois, da cada vez que me mataram,

Foram levando qualquer coisa minha... (p. 101)

Tomado pelo desamparo, o sujeito lírico sente-se empobrecido, conforme se constata no seguinte fragmento:

Hoje, dos meus cadáveres eu sou

O mais desnudo, o que não tem mais nada.

Arde um toco de Vela amarelada,

Como único bem que me ficou. (p.101)

A linguagem do soneto remete, inicialmente, à derrota, uma vez que os quartetos são repletos de significantes relacionados à violência, à morte e à sensação de perda. Porém, à medida que se prossegue a leitura do poema, o sujeito poético passa a demonstrar uma surpreendente confiança na salvação:

\footnotetext{
Vinde! Corvos, chacais, ladrões de estrada!

Pois dessa mão avaramente adunca

Não haverão de arrancar a luz sagrada!

Aves da noite! Asas do horror! Voejai!

Que a luz trêmula e triste como um ai,

A luz de um morto não se apaga nunca! (p.101)
}

Se, por um lado, "arrancaram-lhe" toda a crença na humanidade, por outro, resta ainda a fé na "luz sagrada", um "bem" que ninguém lhe tira da "mão". Essa parte do corpo ganha destaque no poema intitulado "As mãos de meu pai" (p. 491). Por meio de uma linguagem metafórica, o sujeito poético vai esboçando a imagem da mão de um velho, na qual as manchas marrons da idade fazem o "fundo" e as veias grossas, que mais parecem "cordas azuis", surgem em primeiro plano. 
Para o sujeito lírico, o belo se encontra na carapaça marcada pela experiência, uma vez que a luz que surge das "mãos do velho pai" representa esta "beleza que se chama vida". A propósito, o poema apresenta o vocábulo chama em diferentes circunstâncias, fazendo-o variar de classe gramatical de acordo com cada uma delas. No trecho a seguir, bem como na expressão "essa chama de vida", a palavra exerce função de substantivo, na medida em que dá nome à luz que parece vir daquelas mãos:

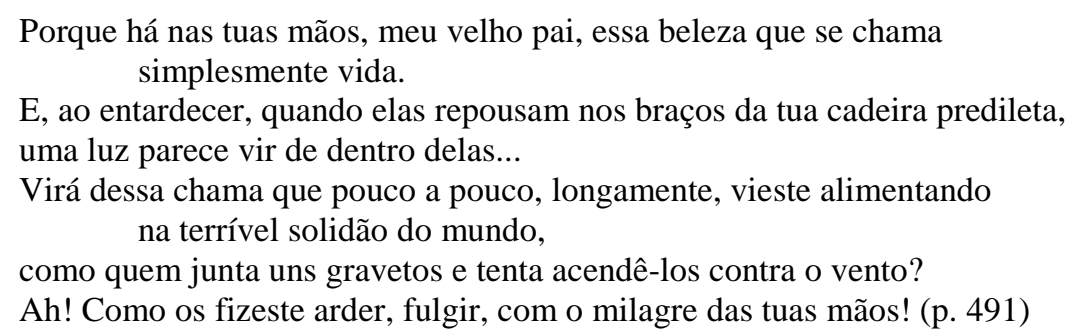

Ao aparecer nos versos "Porque há nas tuas mãos, meu velho pai, essa beleza que se chama/ simplesmente vida", a palavra assume papel de verbo, situação que volta a ocorrer na última linha do poema, quando apresenta desinência de número e pessoa, além de estar conjugado no tempo futuro do modo indicativo: "E é, ainda, a vida que transfigura as tuas mãos nodosas/ ... essa chama de vida - que transcende a própria vida/... e que os Anjos, um dia, chamarão de alma".

A freqüência com que a expressão "chama" faz-se presente no poema, seja na condição de nome ou de verbo, acaba salientando a metáfora da vida que ela representa. Constata-se, também, que o sujeito lírico do poema mencionado vê a velhice como uma "transfiguração" e, ao falar de transcendência, ele demonstra entender que "a luz de um morto não se apaga nunca", mesma crença na ressurreição evidenciada pelo sujeito poético do "Soneto XVII". Dessa forma, a "luz" que emana do velho representa sua própria alma, a beleza interior que sobressai ao invólucro que a contém, idéia confirmada pelo eu-lírico de "Os velhinhos" (p. 901):

\footnotetext{
Como os velhinhos - quando uns bons velhinhos são belos, apesar de tudo! Decerto deve vir uma luz de dentro deles... Que bem nos faz sua presença! Cada um deles é o próprio avô Daquele menininho que durante a vida inteira Não conseguiu jamais morrer dentro de nós! (p. 901)
}

Com base no que fala o poema, pode-se concluir, enfim, que a frase dita pelo poeta lembrada no início deste trabalho - parece ecoar na voz do sujeito lírico de sua obra, pois este também acredita que, ao nos tornarmos velhos, passamos a ser avós "daquele menininho que durante a vida inteira/ não conseguiu jamais morrer dentro de nós!”. 


\section{Em frente ao espelho: as várias faces do velho}

Diante do exposto, fica evidenciado que a velhice é focalizada pelo sujeito poético de Mario Quintana sob distintos pontos de vista. Se, em alguns momentos, privilegiam-se os aspectos negativos do envelhecimento e os preconceitos que incidem sobre o velho; em outras situações, ganham destaque as recompensas que o eu-lírico pode obter e as (re)descobertas que pode fazer enquanto sofre as metamorfoses do processo. De acordo com o enfoque, o poeta lança mão de diferentes recursos, conferindo à imagem do velho nuanças que denotam ironia, lirismo e melancolia. Os poemas analisados demonstram que envelhecer é, antes de tudo, trilhar um caminho que leva a adquirir experiência, ora considerada algo positivo; ora, dispensável. Envelhecer, às vezes, equivale a estar abandonado, esperando a chegada da morte; até porque, de acordo com o sujeito poético, não há diferença entre o velho e o doente terminal. Além disso, aquele que sofre do mal chamado vida longa, ao perder a utilidade, torna-se um indivíduo improdutivo, impotente e, por isso, descartável.

Em compensação, a lírica de Quintana revela que envelhecer é manter viva a lembrança da casa em que se nasceu, e vasculhar os esconderijos da própria memória, desejando de volta os brinquedos que já ganhou e perdeu. É ser "ainda o mesmo menino teimoso de sempre" e não perder a capacidade de sonhar nem de imaginar só porque "envelheceu, um dia, de repente". Tornar-se velho é preservar a fé na "luz sagrada", na "chama", apesar da descrença na humanidade que passa a nutrir com o passar dos anos. Envelhecer é, ainda, encontrar uma imagem ancestral no espelho onde reflete o próprio rosto, e ver nesse mesmo rosto "o tempo escorrer", sem sobressaltos. É reconhecer que foi invadido, "ruga a ruga", pelo "velho pai que já morreu”, e resignar-se, afinal, a uma transfiguração que o leva ao reencontro com sua própria história, com suas próprias raízes. Ficar velho significa ir se desiludindo e com isso obter uma "extraordinária sensação de alívio". Envelhecer para o sujeito lírico da obra de Quintana é, enfim, tornar-se mais leve.

\section{Referências}

BEAUVOIR, Simone de. A velhice. Rio de Janeiro: Nova Fronteira, 1990.

BECKER, Paulo. Mario Quintana: as faces do feiticeiro. Porto Alegre: Editora da Universidade/UFRGS, 1996.

CARA, Salete de Almeida. A poesia lírica. São Paulo: Ática, 1985. 
MOREIRA, Carlos André. O lugar a que pertence o poeta. Zero Hora, Caderno Cultura, Porto Alegre, p. 4-5, 18 fev. 2006.

NERY, Hermes Rodrigues. Fernando Sabino: lições de vida de um menino. Disponível em: $<$ http://medei.sites.uol.com.br/penazul/geral/entrevis/sabino.htm>. Acesso em $20 \mathrm{abr}$. 2006.

O ANJO disfarçado tinha jeito de guri e rosto de avô. Zero Hora, Segundo Caderno. Porto Alegre, 6 mai. 1994.

QUINTANA, Mario. Poesia completa. Rio de Janeiro: Nova Aguilar, 2005. 